\title{
O CAMINHO DE QUIOTO
}

Décio Pignatari

Já passa de cinco décadas o momento abdutivo em que me intriguei com Issa (1763-1827), ou melhor, com um poema de Issa que saltou na minha direção, de entre outros, numa revista americana de larga tiragem (a Esquire, talvez).

O poema: aquele dos descuidados patos humanos em algazarra numa lagoa, sob uma dupla chuva de água e chumbo (espingardas de caçadores à beira-lago), com imagináveis relâmpagos e trovões cenográficos nos bastidores das nuvens.

Pouco tempo depois, estava balbuciando com os olhos a cartilha do kanji (ideograma) sino-japonês, pelos mais variados caminhos e descaminhos: arquitetura tradicional, cinema e teatro japoneses; Ezra Pound: a teoria da dança de Kitasono Katue (de visita ao Brasil), a minha fuga para a Europa. Em Paris, sob a égide amistosa de Pierre Boulez, mergulhado na música experimental do festival do Domaine Musical, tentei decifrar, um tanto divertido, o orientalismo americano de um John Cage e de um Robert Creeley, que me recebeu em posição búdica, em seu apartamento. Em seguida, em Ulm, na Hochshule für Gestaltung, iniciei-me na semiótica de Peirce, na estrutura do ícone e na parataxe. Enquanto isso, em carteio fabricitante com os irmãos Campos, começava a delinear-se o projeto da poesia concreta, que seria lançada no ano de meu regresso ao Brasil, 1956.

Mais uma década, e Gilberto Mendes - raro sobrevivente das batalhas pela nova música - comporia o moteto para o meu poema Beba coca-cola, que teria prolongada repercussão no Brasil e no exterior, com gravações variadas. Os tempos voaram como se incógnitos. Na passagem 1970/1980, o compositor me encomendou um libreto de ópera, sem prazo definido. Com algum entusiasmo, propus o Brás Cubas, de Machado de Assis. O prazo esticou-se por anos, até à minha desistência: não consegui realizar a tarefa, simplesmente. 
Há vinte anos, exatamente, graças a uma bolsa da Fundação Japão, de São Paulo, vi-me em andanças outonais nipônicas. Depois da complexa rigidez de Tóquio, a distensão graciosa e gostosa de Quioto, onde achei um precioso livrinho sobre Issa, Autumn wind, de Lewis Mackenzie, com minibiografia e ensaio, seletânea de poemas, com kanjis, transcrições fonéticas, versões lineares, etc. No caminho ao longo de um riacho que serpeava tranquilo por um descampado em pleno setor urbano, fui tomado pela súbita tentação de fazer um libreto sobre Issa. Lembrando-me de Oscar Wilde - "O melhor modo de livrar-se de uma tentação é entregar-se a ela" - foi o que fiz.

Numa daquelas noites quiotanas, fui a uma apresentação cênico-poética de Allen Ginsberg. Havia gente pendurada até no lustre. Ao fim do espetáculo, enquanto a sala se esvaziava e ensombrecia, fui no contrafluxo, subi ao palco, invadi as coxias, apresentei-me e dei um abraço no poeta, embora a literatura beat não me dissesse grande coisa. Supostamente, lembrou-se do meu nome e da poesia concreta brasileira, e perguntou o que fazia eu no Japão. Esnobei um tanto, como se soubesse o japonês que mal sabia: "Traduzindo Issa" Excuso-me e me escudo em Pound: "I work in concentration"

Em Curitiba, onde vivo, costumo caminhar pelo vizinho Bosque do Papa. Para uso de meu ego folclórico, batizei de Caminho de Quioto o meu "waldweg" preferido, um pequeno trecho entre a fímbria ocidental do bosque e o riacho Belém canalizado. O Caminho de Quioto finge favorecer o meu pensar, sempre tentado pela dispersão. Foi ali que me ocorreu desenhar a grande tira colorida da passagem da comitiva do Daymio (senhor feudal) pela aldeia de Issa, com alguns acenos musicais de meu errático repertório ("Fêtes", de Debussy; "Parade", de Satie; escolas de samba, etc.), destinada a a atiçar a inspiração de Gilberto Mendes.

Nossos contatos, diretos e indiretos, sempre foram rarefeitos, o Giba jamais abandonando a sua adorada cidade de Santos. Quando me transferi para Curitiba, em 1999, a distância aumentou também no tempo. Na presente e corrente década deste século, lembro apenas de ter ouvido duas versões da abertura da ópera (a segunda era a melhor); de haver dado um depoimento para um documentário cinebiográfico realizado pelos seus filhos, e de ter lido, nos jornais que o compositor submetera uma obra musical, com temática de "mata atlântica" a um certame público, não tendo sido contemplado. Quanto ao mais (sublinhe-se o mais): Não tenho interesse em orientalismos de ascese. TAO, de Lao-Tsu, sim; taoísmo, não; zenbudismo: nem falar. Tenho o TAO pelo pensar mais próximo da ontologia ocidental moderna (Heidegger). $\mathrm{TAO}=$ a cabeça a caminho; $\mathrm{TAO}=$ ação sem atos, $\mathrm{TAO}=0$ vazio do vaso; LAO-TSU = o filósofo inencontrável, vida que se oculta da existência, existência que se oculta da vida. (Vez por outra, convoco as sombras de Epicuro e Demócrito). Daí as minhas "taoduções" de Issa, e da "Visita a um taoísta", de Li-Po (ver 31 poetas, 214 poemas, nova edição pela Editora da Unicamp, Campinas, SP, 2007). 
Ópera em dez segmentos

Libreto: Décio Pignatari

\section{Parte I}

Cena dividida em dois planos, superior e inferior - deuses (bodisatvas) e humanos. Ocupando todo o fundo, a silhueta do monte Fuji, com um caracol que começa a subir pela vertente. Desenhos de luzes e cores (neon, p.ex.).

\section{Plano A}

Nuvens, vento, sol, luz, neve, chuva, gotas de orvalho pela campina ou em flores, etc. sucedem-se, marcando estações. Um tema recorrente, o Outono, com árvores e folhas rubro-ferrugem de muitos matizes caem revoluteando. Silhuetas luminosas de budas e bodisatvas piscam, em movimento, como em estroboscopia. Cordas, flautas e vozes dos santos budistas, meio em falsete, joco-sérios sussurram o nembutsu, oração a Amida, encarnação do Buda da Terra Pura, seita a que se filiará, até certo ponto, Issa:

\section{"Namu Amida Butsu" \\ (Honras a Amida, O Buda)}

(Animação) Da boca dos bodisatvas saem os ideogramas - os seis ideogramas - que indicam o Santo Nome do Corpo Definitivo do Buda numa Forma Provisória.

\section{Plano B}

Mímica, canto e dança.

Praça de aldeia, com estradas-ruas confluentes. Casa de Issa (Yataro) à direita, com terreno e plantação. Estalagem, cavalos, burros, bichos. Casa do prefeito. Templinho ao longe. Terras cultivadas, moças plantando e colhendo. Comerciantes, viajantes. Yataro, pai, mãe, avó. Professor e crianças saindo da estalagem. As crianças começam a brincar de esconde-esconde:

Onde você está agora?

Onde você está agora?

Estou aqui

Estou aqui 
Onde você estava?

Onde você estava?

Eu não estava

Eu não estava

Onde você estará?

Onde você estará?

Eu não estarei

Eu não estarei

\section{A e B}

Grande lua prateada se projeta sobre tudo.

\section{Voz do pai:}

- Yataro, ouça isto:

$\begin{array}{ll}\text { Aka aka ya } & \text { clara clara luz } \\ \text { Aka aka aka ya } & \text { clara clara clara luz } \\ \text { Aka aka ya } & \text { clara clara luz } \\ \text { Aka aka aka ya } & \text { clara clara clara luz } \\ \text { Aka aka ya } & \text { clara clara luz } \\ \text { Aka aka aka ya Tsuki } & \text { Clara clara clara LUA }\end{array}$

(Myôe, 1173-1232)

Voz do professor:

- Yataro, ouça isto:

Now that the plaNET

NET

NET

is at peace

at last

we can't prevent

some desease

some desease 
Take it easy

Please

Voz da avó:

- Yataro, ouça isto:

$\begin{array}{lc}\text { Tsuyu Tsuki } & \text { O orvalho a luz } \\ \text { Tsuyu Tsuki } & \text { o orvalho a luz } \\ \text { Tsuyu Tsuki } & \begin{array}{c}\text { orvalho a lua } \\ \text { orvalua } \\ \text { orvalua } \\ \text { orvalua }\end{array}\end{array}$

Irrompe a fanfarra - Corteio do Davmio (Senhor feudal)

Desfile de bonecos em silhueta: sombras, luzes, cores. Começa elevado, com o daymio a cavalo e vai baixando até os serviçais e as bagagens, passando por samurais, palanquins, senhoras, concubinas, gueixas, guerreiros, valetes, cortesãos, etc. Estandartes, alabardas, armas de fogo (canhões, mosquetes), lanças, espadas.

Todos reverenciam, incluindo os bodisatvas do Plano A.

Conforme sons e imagens esmorecem, encerrando a cena, o piso que divide os planos sobe um pouco. E continuará a subir ao fim de cada segmento.

\section{Parte II}

Morte da mãe. Interlúdio do outono.

\section{Plano A}

Os santos fazem a mímica da morte e enterro da mãe. Preto e branco.

\section{Plano B}

Grande bétula ou pinheiro, imitando o Fuji, com folhas caindo, do verde ao vermelho e cobrindo o corpo da mãe deitado na praça vazia. Sons de "wo-wo" (cachorro) e "ko-ko" (go-go) (corvo). 
Tema dos 6 ventos:

1. Vento fresco (cigarras, brumas)

2, Vento menos fresco (algodão)

3. Vento frio (orvalho, gansos selvagens, cala-se o grilo, abrem-se os crisântemos)

4. Vento de geada, aguaceiros, árvores se avermelhando

5. Tufões, lua cheia, colheita do arroz, novas constelações (Ursa Maior, Andrômeda, Altair, Cisne, Peixes)

6 . Vento gelado, orvalho gelado (tsuyuyzamu)

Lua sobre campo ceifado azul.

Grande ressonância do som no ar límpido e no céu vazio

Voz cava da moribunda:

- Yataro!

De dentro do monte de folhas, sai o pai com noiva nova.

Voz do outono: sopro e cordas. Canto do cuco.

Grande outono grande

Mas aquele passarinho

Cresce como o céu

Solidão. Vozes e sons saem das coisas, em planos diferentes, variando em torno da palavra "Akikaze" (vento de outono).

Akikaze

Akikaze

Outovento

Ventoutono

tono tono tono

vento vento vento 


\section{Parte III}

\section{Plano B}

Animação. Aldeia e paisagem se transformam em dois corpos transando, ondulando lentamente. Não se vêem cabeças, nem pés. $O$ vento passa a ofego e a resfolego. O texto é composto de duas palavras em dueto-duelo - os dois nomes dos filhos trocadas entre pai e madrasta:

\section{- Yataro! \\ - Senroku! \\ - Yataro! \\ - Senroku!}

As palavras podem ser misturadas aos sons "zen" (bem) e "aku" (mal).

\section{Plano A}

Os santos também ondulam, fazem "onda" ("ola"), murmurando o "nembutsu" ao ritmo do vai-e-vem do casal.

\section{Plano B}

O casal gira, aparece a madrasta de frente, em posição ginecológica. De dentro da vagina, sai ela mesma, em ondas sucessivas, de pé, vestida, segurando o bebê em exibição, com as duas manos gritando, entre vitoriosa e alucinada:

\section{— Senrôku! \\ - Senrôku!}

O Plano A vai apagando. Só se ouve o murmúrio da prece, cortado pelos gritos da madrasta.

\section{Plano B}

Vista geral da aldeia. A cada grito estremece um componente: casa, estalagem, árvore, templo etc. Em flash-vagalume, acende-se um santo (Plano A) no escuro, assustado. Tema do vento (cortante): 
- Yataro, carregue o menino!

- Yataro, vá tecer sandálias!

- Yataro, colha legumes!

- Yataro, lave os cavalos!

- Yataro, pare de ler!

- Yataro, chega de escola!

- Yataro, pare de escrever!

- Yataro, apague o lampião!

- Pare de chorar, moleque!

Voz do professor:

- Vá embora daqui, Yataro. Um dia, Amida e seus santos descerão pela estrada branca de neve, para levá-lo à Terra Pura - Jodo! Jodo! Jodo!

Voz do pai:

- Vá para Edo meu filho.

Toque pra Tóquio

Vá sem medo.

\section{Plano A}

Santos caminham de um lado para outro, entoando hinos e torcendo para Yataro. Comicidade.

\section{Plano B}

Cena de multidão de feira, à beira-rio. Barracas, verdureiros, daymios, cortesãos, prostitutas, mendigos, músicos.

Em telão, "zoom" em Issa adolescente, no meio da multidão.

Sucessão de cenas mostrando os empregos de Issa.

1. Issa cavalariço, em cocheira. Noite. À luz de um candeeiro, lendo e escrevendo. Mosquitos piscando. Cavalos protegidos por mosquiteiros. Fala caipira de Issa:

— Oi, pangaré, Mecê num qué cambiá de lugá comigo?

- (Relincho)

2. Issa copista em casa de comércio. Implementos de escritura. Moças empregadas passam e riem. 
- De onde você vem, Yataro?

- Kashiwabara.

- Onde é isso.

- Shinano.

— Onde é isso?

- Não é aqui, suas galinhas!

- (Cacarejos)

3. Cortando legumes em cozinha. Aparece um sapo na soleira.

- Quando eu souber sentir como você, vou ser poeta.

- (O sapo coaxa).

- (Issa peida).

\section{Plano A}

Bodisatvas continuam comentando a ação. Dançam. Gesticulam. Põem dedos no nariz, se agacham, dançam em roda.

\section{Plano B}

Grande plano. Tudo em tom de flor de cerejeira. Escola de haicaístas de Katsushita, discípulo de Bashô. Issa jovem.

Depois dos crisântemos

Para lá do grande nabo

Não há nada

(Bashô)

\section{Plano A}

Santos põem mãos nas cabeças. Entoam o nembutsu, jogando beisebol. Zoom em Amida-beisebolista catando bola:

\section{$\underline{\text { Santos: }}$}

- Oh!

Amida:

- OK! 


\section{Plano B}

No meio da classe, surge do chão, lentamente, uma bananeira (Bashô), que fala:

- Não meta palavras

Entre nós e a verdade

Nem antes nem depois

Nem acima nem abaixo

Nem de um lado nem de outro

Nem dentro nem fora

Diga sempre: É isso!

Não foi nem será: é isso!

é agora

apenas agora

- O que ponho, então?

- Todo o resto.

$-\mathrm{E}$ as palavras?

- Também.

(Fade out)

Katsushika morto. Discípulos lamentam em volta. Incensos excessivos. O mestre, em vestes talares, ricas, ressuscita sob a forma de Issa, andrajoso, malcheiroso, malquisto. Discípulos se afastam, dedos nos narizes. Issa, 28 anos.

\section{Coro de discípulos}

Issa não é haikai

Yotaro não é haikai

Issa não é haikai

Yotaro não é haikay

Issa não é haikai

Issa não é haikai

etc.

\section{Plano A}

Santos fazem movimentos diversos, alguns imitam os discípulos: dedos nos narizes, nos olhos, nos ouvidos, na boca, no traseiro. Risadas. 


\section{Plano B}

Yotaro abre caminho entre os discípulos e parte - rumo à aldeia natal:

Furusato ya!

(Volto pra casa!)

Multipainel de pés com sandálias caminhando ao compasso de:

\section{Furusato ya!}

(Corte rápido)

Cerca de espinhos, com orvalho/lágrimas gotejando. Ao longe, a casa. Imagens destorcidas, anamórficas. $O$ velho pai acenando, ao longe.

Mesmas imagens do multipainel, em sentido contrário: volta a Edo (Tóquio). Festa de amigos: raspagem da cabeça, estamenha de monge, cajado, sandália de palha, chapéu (kasa). Cerimônia iniciática (olhos vendados):

(Coro)

— Quem é você?

- Meu nome é Issa.

- Quem é você?

- Eu sou a bolha.

- Quem é você?

- A bolha que desliza na superficie do bule de chá, por um segundo.

— Quem é você?

- O orvalho do chá.

— Quem é você?

- Eu não sou Issa.

- Quem é você?

- Eu sou aquilo.

— Quem é você?

- Issa é a lesma, o Sapo, a pulga, a flor

— Quem é você?

— Eu sou Issa-Agora 
Baixam, sucessivamente, 3 grandes cortinas transparentes: a) casa com chaminé fumegando; b) chaleira soltando vapor; c) ideograma de Issa (茶) :

(pisca-pisca/canção)

\title{
Parte IV
}

\section{Plano A}

Bodisatvas metem cabeças à espreita, para assistir à:

\section{Plano B}

Morte do pai de Issa e disputa pela propriedade.

Coro da expulsão: prefeito, madrasta, meio-irmão, vizinhos, estalajadeiro, aves, bichos, árvores, pedras, objetos:
A terra é dela
A casa é dela
Ela sua
Ela se suja
Ela trabalha
Até o filho trabalha
Você é sujo
Mas não sua
Você não trabalha
Suma daqui
Você atrapalha

\section{O professor:}

\author{
Mas ele é poeta \\ Trabalha em outra terra!
}

\section{Coro:}

Então não precisa desta

Então não precisa desta

Etc.

Issa parte, mochila às costas. 


\section{Plano A}

Santos imitam, em ritmo de conga, mas de costas. Entoando, junto com o nembutsu, a palavra Jodo (Terra Pura). Santos dançam em fila, em ritmo de conga, de um extremo a outro. O limite, uma barra negra - vai subindo, a espremê-los... Nembutsu em tempo de conga.

\section{- A caminho! \\ - On the road! \\ - Pé na estrada!}

\section{Plano B}

Fusões sucessivas de mão escrevendo com estilete ou pena, em várias direções ou caracteres. Vez por outra, flashes de caracol subindo o Fuji.

Telão exibe scrambled documentário dos séculos XIX e XX, quase irreconhecíveis.

\section{Locutor:}

E assim Issa peregrinou durante 4 anos pelas províncias do Oeste. " $\mathrm{Al}$ ritorno..." (Música: Fusão de motivos de "La boheme" c/ "Umn bel di vedremmo", da Butterfly) (Fade out)

\section{Parte V}

\section{Plano B}

Grande display de poemas (haicais).

No cenário, ampliações metonímicas flutuantes, luminosas, multicoloridas: púbis e coxa de mulher; focinho e olho de sapo; cabeça de pulga; cabeça de gralha; corvo; folha rubra de outono; enorme gota de orvalho; focinho de gato segurando uma lua cheia; vagalume; pato; puta.

Uma sucessão de haicais, em painel: ideogramas. Acende-e-apaga. Tudo em flash. Issa ao centro, quase de costas (auto-retrato com ideograma).

\section{Plano A}

Letreiro em rainbow. Figurinhas dos santos em desfile, entremeadas de sons dos haicais. 
Os poemas:

"Mais alguém?" - zombou

O moço do hotel. "Comigo,

Só migo", disse Issa.

Cavo direitinho

$\mathrm{Na}$ nave que invade a porta

Um poço. Mijando.

A folha espirala.

A pata do gato a agarra

Só por um tempinho.

Pouca gente

Folha pouca

Indo aqui e ali

Hito chirari kono ha mochirari horari kana

Uma carga d'água

Naquele cavalo em pêlo

E eu em pêlo nele

Grande pirilampo

por-aqui-por-ali-per-

passou pelo campo

Veja a primavera

Veja, lá longe, ondulando

Na grama - agora!

Vá devagar cara -

Ao topo do monte Fuji

- col, vá devagar

Aos pássaros, aos

não-pássaros, nossos campos

"Ame-a já!" - proclamam 
Pérolas de orvalho!

Olho e vejo em cada folha

A minha casa-espelho

Lago pingos tiros:

quá - quá - quá dos patos patos

por enquanto vivos

Mordidas de pulgas

na moça bonita: até

elas ficam belas!

Quanto inseto canta!

Ócio. Formiga silen-

ciosa mostra a bunda.

Já foi feita a escolha?

Chegou minha vez, é isso?

Gralha barulhenta!

Do primeiro banho

- tatibitatepatáqua -

ao último banho.

(A cena se fecha com grande eguicho de mijo vindo do alto)

\section{Parte VI}

\section{Plano A}

Santos, cada vez mais espremidos, agachados, em suas vestes brancas, jogando pétalas de flores para baixo.

\section{Plano B}

Teatro de sombras. Kashiwabara. Paródia da comitiva de um daymio, Issa à frente, ou melhor, atrás de um funcionário que lê um edito ou proclamação. Sombras grandes, seguidas de sombras de bichos, de um cavalo a uma formiga. À frente, o pessoal da aldeia, incluindo o prefeito e os espoliadores - sombras bem pequenas. Em vários 
telões, cenas da ascensão de Issa: a) cercado de discípulos, que copiam os poemas; b) um daymio que se dedigna a descer de um cavalo para render-lhe uma homenagem; c) sendo recebido por um rico comerciante, com banquete, músiscos e dançarinos; d) numa casa de gueixas, deitado com uma cortesã, etc.

Coro dos bichos e dos santos, cacofonia misturada:

Casa de Issa

Casa de Issa

Terra de Issa

Terra de Issa

Jodo Jodo

Terra Pura

Terra Pura

Tudo em partes iguais

Animação: num telão, corre um muro ou tabique que divide casa e terra ao meio.

Grande voz do Grande Corvo:

Agora, Issa
precisa casar

Aa silhuetas se iluminam, transformando-se em desfile matrimonial.

\section{Parte VII}

Os casamentos

\section{Plano A}

Santos entoam nembutsu com lances de marcha nupcial, que vai virando marcha fúnebre.

\section{Plano B}

Um grande crisântemo (Kiku) e uma grande chaleira (Issa) ocupam toda a cena. No centro da flor, uma vulva, que começa a vibrar, vai-se abrindo e soltando pequenos crisântemos. Estes caem ao chão. Estes caem ao chão, dançam alegres e vão morrendo, um a um. 
Ciranda dos crisântemos mortos.

(Morte da filhinha Sato - 3 ou 4 anos)

(Cobrem-lhe a cabeça com capuz de saco de arroz, mergulham o corpo em tina de água com sakê, para expulsar os maus fluídos e maus espíritos da varíola que a matou).

Issa:

Um saco de arroz

Um banho com sakê

Você que a levou

Vá embora também

Varíola varíola

Vá embora também

A vida-orvalho não dura

A vida-folha só cai

Onde a Terra-Pura

Filha folha

Folha filha

Mais bela que os 25 santos

com suas flautas e cordas

A vida-orvalho não dura

E no entanto

E no entanto

E no entanto...

(Uma única folha vai caindo do alto, lentamente)

O grande crisântemo também vai murchando.

Voz do Grande Corvo: "Issa precisa casar"

Animação: Issa levando noiva para dentro de casa. Issa deitando-se com noiva. Noiva saltando da cama. Noiva tapando nariz com dedos. Noiva indo embora.

Voz do Grande Corvo: "Issa precisa casar" 
Cena total. Telão. Grande cama. Issa, velho, por baixo. Esposa por cima. Caracol se anima na escalada do Monte Fuji.

Ameixeira. Amor.

Dura pouco por que dura:

Flor flor flor flor flor

Vem a neve em mim

Mas ela me aquece assim

Pois nela floresce

\author{
Ponho a mão \\ nas suas coxas: \\ todos os frios das minhas vidas \\ pedem perdão.
}

FADE OUT seguido de raio e trovão. Ideograma de Issa pegando fogo. Casa queimada. Issa e mulher num galpão minúsculo, de meio teto. A neve cai sobre o cobertor.

Terra Pura Terra Pura

Neve Pura Neve Pura

Vocês sofrem como nós?

Carne Pura Carne Pura

Nagara nagara

A criança não para de mexer-se

na barriga da mãe

Quem será?

Quem vai ser?

Quentinha...

Plano A

Santos espremidos contra o teto, só as cabeças pra fora.

\title{
Parte VIII
}

Parábola do Jogo de Xadrez 
Grande tabuleiro de xadrez estendendo-se na perspectiva de um campo. Pequenas telas mostram as peças: ora um rei, ora uma rainha, uma cavaleiro, um sacerdote, um peão camponês. Numa tela grande, o jogo armado. Passa uma grande mão, joga todas as peças numa caixa.

Damas todas, essas, e reis, jogadas na caixa: peças de xadrez.

\section{Parte IX}

\section{(As paralisias de Issa)}

(Sombra de Issa atravessa campo lavrado da aldeia, como uma nuvem - Issa apoiado num cajado. De vez em quando ele estaca, se paralisa. Um poema cantado, em cada parada):

(O caracol já está atingindo o topo do Fuji)

Já foi feita a escolha?

Chegou a minha vez, é?

Gralha barulhenta!

Estou virando presente puro

Onde me põem eu fico

Como me põem eu fico

O primeiro banho

- tatibitatepatáqua -

$\mathrm{O}$ último banho

\section{Parte X}

O poema "terra", de DP, é projetado em perspectiva sobre o campo lavrado. O caracol chega ao topo do Fuji. No meio da terra, o ideograma de Issa transformado em espantalho. Num telão, em realidade virtual, a casa de Issa, moderna, com a inscrição - "Propriedade de Issa" Sucedem-se projeções do poema, em português, inglês e 
japonês. Do plano A, com os bodisatvas já prensados, começa a cair uma cortina de neve - branca, a princípio; depois, em cores irisadas, depois branca. O nembutsu final é um coral em torno das palavras "Jodo", "Terra Pura", "Terra Limpa"

Fade out final

dpignatari
valdevinos, dezembro 95

\section{Issa}

\section{Observações}

1. obra ópera é concebida segundo uma leitura "zemiótica", montada sobre a idéia de "secundidade", de Peirce. Trata-se de uma ópera sobre "o agora" de toda e qualquer coisa, de sua presentidade, sem antes, nem depois, sem passado e sem futuro.

Quanto à visualidade, p. ex., imagino tudo fora de foco, entrando em foco apenas o que está em ação.

2. Uma ópera inteira em "flashes", uma ópera-vagalume.

3. Uma operação especial para os textos. Só às vezes eles devem aparecer claramente, com sentido claro, ou melhor, cada texto é apenas um momento do texto, um momento em foco de um texto-som muito maior. Imagino uma operação bastante simples... que é bastante complicada! Para cada palavra ou linha, usem-se: a) as consoantes anteriores e as posteriores; $b$ ) as vogais anteriores e as posteriores; $c$ ) as combinações. Uma computadorização vai fazer-se necessária. Ex.:

$\begin{array}{lll}\text { dokga } & \text { folha } & \text { gomja } \\ \text { filhu } & & \text { fulhe }\end{array}$

etc etc!

4. Ou algum outro meio mais blocalmente estocástico....

5. Uma ópera acende-apaga, com efeito mesmerizante. Provavelmente, isto acarretaria uma grande compactação no tempo. Quanto tempo pode alguém suportar um ópera vagalume? 


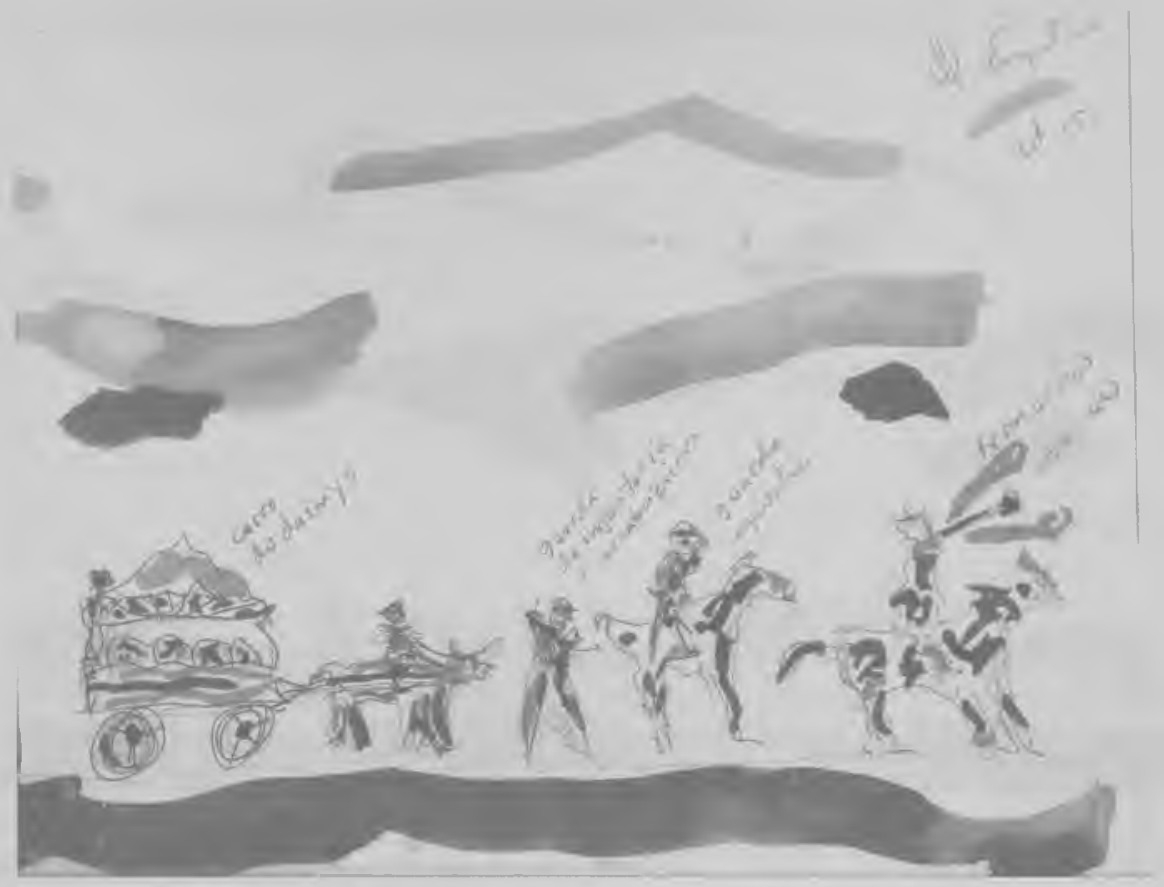

\section{is $511^{\prime \prime}$}

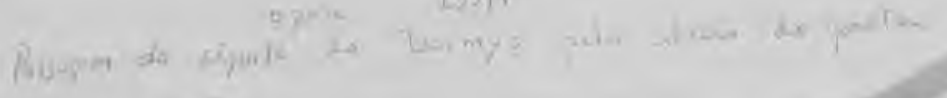

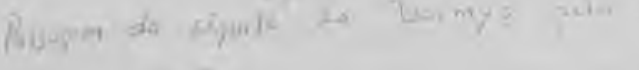
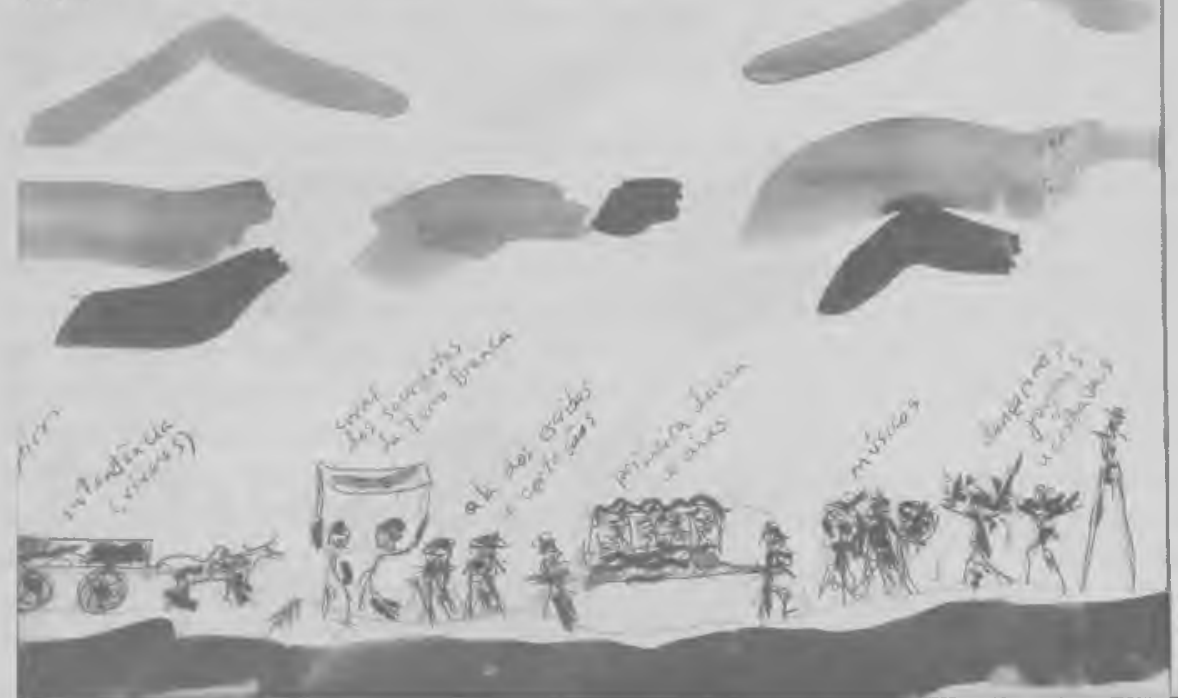

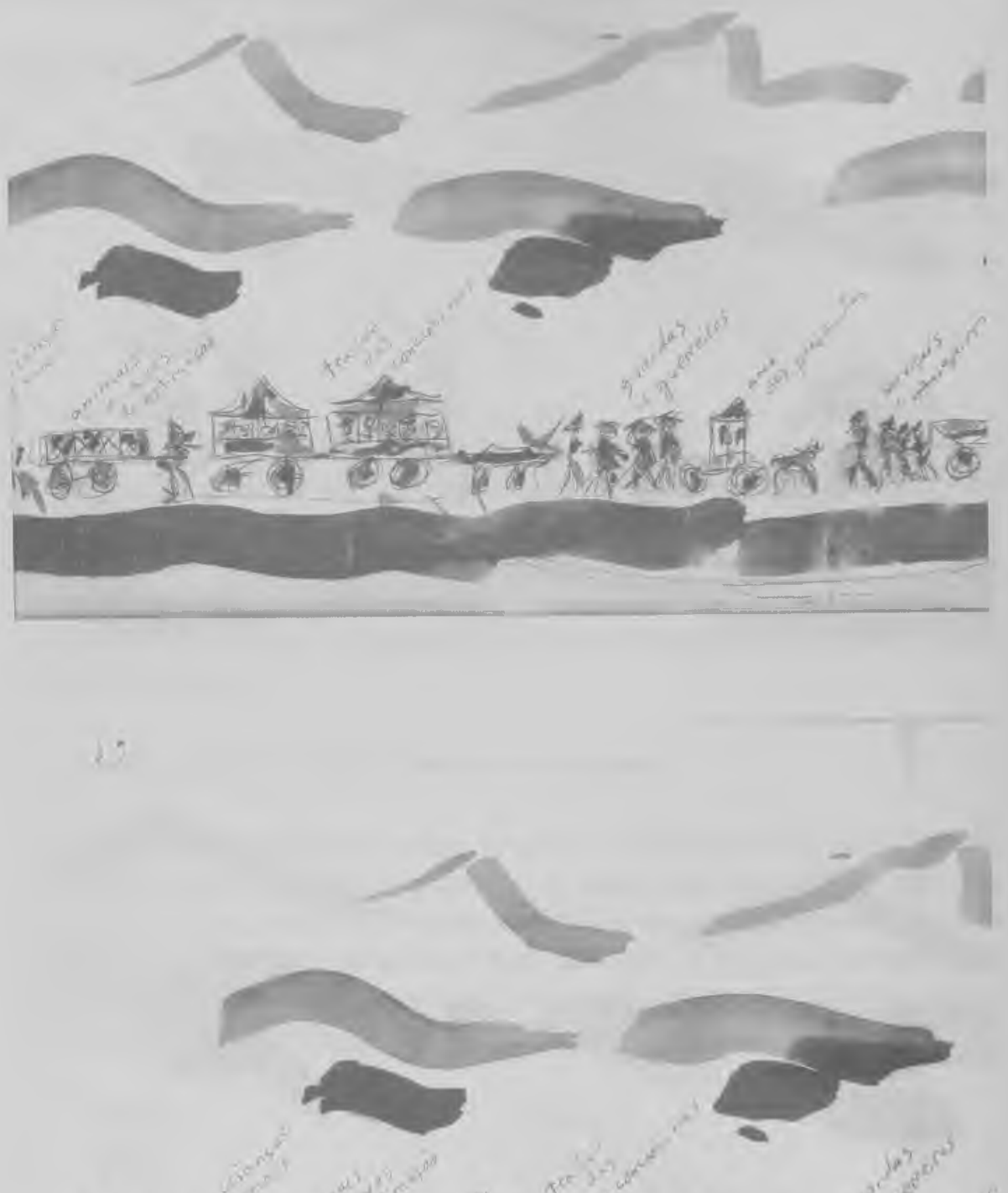

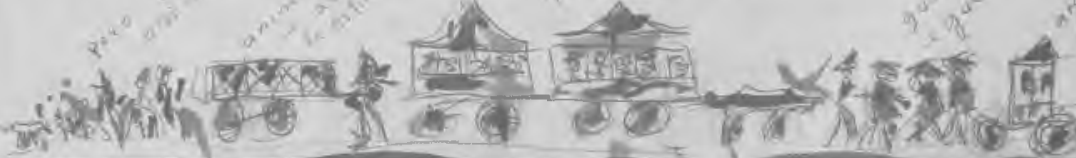
y. 